CLINICAL STUDY

\title{
Short-term treatment with olanzapine does not modulate gut hormone secretion: olanzapine disintegrating versus standard tablets
}

\author{
Solrun Vidarsdottir, Ferdinand Roelfsema, Trea Streefland, Jens J Holst ${ }^{1}$, Jens F Rehfeld ${ }^{2}$ and Hanno Pijl \\ Department of Endocrinology and Metabolism, Leiden University Medical Center, 2300 RC Leiden, The Netherlands, ${ }^{1}$ Department of Biomedical Sciences, \\ The Panum Institute, University of Copenhagen, Copenhagen, Denmark and ${ }^{2}$ Department of Clinical Biochemistry, Rigshospitalet, Copenhagen, Denmark \\ (Correspondence should be addressed to H Pijl; Email: h.pijl@lumc.nl)
}

\begin{abstract}
Background: Treatment with olanzapine (atypical antipsychotic drug) is frequently associated with various metabolic anomalies, including obesity, dyslipidemia, and diabetes mellitus. Recent data suggest that olanzapine orally disintegrating tablets (ODT), which dissolve instantaneously in the mouth, might cause less weight gain than olanzapine standard oral tablets (OST).

Design and methods: Ten healthy men received olanzapine ODT (10 mg o.d., 8 days), olanzapine OST (10 mg o.d., 8 days), or no intervention in a randomized crossover design. At breakfast and dinner, blood samples were taken for measurement of pancreatic polypeptide, peptide YY, glucagon-like peptide-1, total glucagon, total ghrelin, and cholecystokinin (CCK) concentrations.

Results: With the exception of pre- and postprandial concentration of ghrelin at dinner and preprandial CCK concentrations at breakfast, which were all slightly increased (respectively $P=0.048, P=0.034$ and $P=0.042$ ), olanzapine did not affect gut hormone concentrations. Thus, olanzapine ODT and OST had similar effects on gut hormone secretion.

Conclusion: Short-term treatment with olanzapine does not have major impact on the plasma concentration of gut hormones we measured in healthy men. Moreover, despite pharmacological difference, gut hormone concentrations are similar during treatment with olanzapine ODT and OST. The capacity of olanzapine to induce weight gain and diabetes is unlikely to be caused by modulation of the secretion of gut hormones measured here. We cannot exclude the possibility that olanzapine's impact on other gut hormones, to impair insulin sensitivity and stimulate weight gain, exists.
\end{abstract}

European Journal of Endocrinology 162 75-83

\section{Introduction}

The use of atypical antipsychotic (AP) drugs is associated with obesity $(1,2)$ and diabetes mellitus (3). The mechanism underlying these serious metabolic side effects is unclear. Olanzapine, one of the atypical AP drugs, which is extensively used to treat schizophrenia and (more recently) bipolar disorders, has offered a valuable alternative to the older 'typical' AP drugs, which have major (CNS) side effects. Currently, two types of olanzapine tablets are available for clinical use: standard (oral standard tablets (OST)) and orally disintegrating (orally disintegrating tablets (ODT)) . Two recent papers report that treatment with ODT might be less harmful in terms of weight gain than treatment with OST $(4,5)$; while Arranz et al. reported significantly less weight gain in subjects treated with ODT versus OST for 6 weeks ( 3.3 vs $6.6 \mathrm{~kg}$ respectively), de Haan reported significant weight loss after switching from OST to ODT (in 16 weeks $6.6 \mathrm{~kg}$ weight loss versus $3.3 \mathrm{~kg}$ weight gain in subjects treated with OST).
The main pharmacological difference between these compounds is that ODT dissolves instantaneously in the mouth upon administration allowing absorption through the sublingual mucosa. Administration of the ODT formulation, therefore, results in an earlier detection of the drug in the plasma than OST (6), while the maximum plasma concentration $\left(C_{\max }\right)$ and the time until the maximum plasma concentration is reached $\left(T_{\max }\right)$ are similar for both compounds $(6,7)$. Thus, it is unlikely that distinct effects on central neurotransmission explain the different effect of ODT and OST on body weight.

The gastrointestinal (GI) tract is richly innervated by the enteric nervous system (ENS), which controls and coordinates enteric behavior, including motility, blood flow, and secretion (8). In recent years, a variety of peptide hormones have been identified. They are released from the gut in response to food intake and deprivation (9). These gut peptides are involved in the regulation of energy balance (9). Some evidence suggests that the ENS modulates gut hormone synthesis 
and secretion. For example, ghrelin-secreting cells express the vesicular monoamine (MA) transporter 2 (10), suggesting a role of monoaminergic neurotransmission in ghrelin secretion. Also, secretion of glucagon-like peptide-1 (GLP-1) $(11,12)$ and peptide YY (PYY) (13) is stimulated by cholinergic muscarinic receptor agonists and blocked by atropine $(11,13)$. Since many of the small MA neurotransmitter receptors in the CNS have also been identified in the ENS, it is conceivable that olanzapine, which blocks many of these receptors, also affects neural circuits in the ENS.

We hypothesized that olanzapine impacts on gut hormone release to explain its characteristic to induce obesity and type 2 diabetes. We also proposed that treatment with ODT, which is absorbed through the sublingual mucosa and therefore presumably exerts less influence on MA receptors in the GI tract, would have less impact on gut hormone secretion than treatment with OST to explain their distinct impact on body weight. Here, we compare the early effects of the two forms of olanzapine tablets on pre- and postprandial gut hormone concentrations in healthy men.

\section{Method}

Twelve healthy men between 20 and 40 years were recruited through advertisements in local newspapers. The subjects were required to have a stable body mass index (BMI) between 20 and $27 \mathrm{~kg} / \mathrm{m}^{2}$ and a normal fasting plasma glucose concentration $(<6.0 \mathrm{mmol} / \mathrm{l})$. Subjects who had ever used AP medication, and subjects who were currently smoking or using medication affecting the CNS were excluded. All subjects provided written informed consent after explanation of the study procedures and possible adverse effects of the treatment. The protocol was approved by the medical ethics committee of the Leiden University Medical Center and registered by www.controlled-trials.com (ISRCTN17632637).

\section{Drugs}

All subjects received olanzapine standard tablets (OST; $10 \mathrm{mg}$ o.d. for 8 days), olanzapine ODT (10 mg o.d. for 8 days), or no intervention in a randomized crossover design. The drugs were taken at $0800 \mathrm{~h}$ except on day 8 when they were taken at $0700 \mathrm{~h}$. The minimum plasma concentration $\left(C_{\min }\right)$ of olanzapine was determined on day 8 at $0700 \mathrm{~h}$ by HPLC with u.v. $(\lambda=270 \mathrm{~nm})$ detection. The detection limit of olanzapine was $5 \mu \mathrm{g} / \mathrm{l}$.

\section{Diet}

To limit confounding by nutritional factors, subjects received a standard diet containing $2400 \mathrm{kcal} /$ day on days 7 and 8 of each intervention period. The diet consisted of bread, fillings, and drinks, prepared by the research center. The macronutrient composition of the diet was exactly the same on all occasions: $48 \%$ of total ingested calories from carbohydrates, $17 \%$ from proteins and 35\% from fat. Intake of alcohol and caffeine/theine containing beverages was not allowed the day before and during all study occasions.

\section{Clinical protocol}

Subjects were studied thrice in random order; without an intervention (control) and after treatment with olanzapine OST (10 mg o.d., 8 days) and ODT (10 mg o.d., 8 days). There was a time interval of at least 6 weeks between each study occasion. On day 7, after a 10-h overnight fast, body fat percentage was determined by bioelectrical impedance analysis (BIA; Bodystat 1500 MDD, Bodystat LTD, Douglas, Isle of Man, UK). At this time point, the subjects were prescribed the standard diet delineated earlier. Subjects were re-admitted to the research center at $1700 \mathrm{~h}$. A cannula for blood sampling was inserted into an antecubital vein. Blood samples were collected with S-monovette (Sarstedt, Etten-Leur, The Netherlands) from a three-way stopcock that was attached to a $0.9 \%$ $\mathrm{NaCl}$ infusion $(20 \mathrm{ml} / \mathrm{h}$; with $100 \mathrm{U}$ heparin/500 ml $)$ to keep the cannula from clotting. Blood samples were taken at $20 \mathrm{~min}$ intervals as from $1 \mathrm{~h}$ prior to until $2 \mathrm{~h}$ after each meal, and after that every $30 \mathrm{~min}$ until $4 \mathrm{~h}$ after each meal (dinner on day 7; breakfast on day 8) for measurement of pancreatic polypeptide (PP), PYY, GLP-1, total glucagon, total ghrelin, and cholecystokinin (CCK) concentrations. Total glucagon was measured in order to estimate oxyntomodulin (and glicentin) concentrations in response to meals. At $0700 \mathrm{~h}$, the drug was taken. Dinner and breakfast were served at 1830 and $0800 \mathrm{~h}$ respectively. Subjects remained sedentary except for bathroom visits; at $2300 \mathrm{~h}$, lights were switched off.

\section{Assays}

Blood was sampled in EDTA tubes to which Trasylol had been added $(40 \mu \mathrm{l} / \mathrm{ml}$ blood $)$. Each tube was immediately chilled on ice. Samples were centrifuged at $2630 \mathrm{~g}$ at $4{ }^{\circ} \mathrm{C}$ for $20 \mathrm{~min}$. Subsequently, plasma was divided into separate aliquots and frozen at $-80{ }^{\circ} \mathrm{C}$ until assays were performed. One mmol/l $\mathrm{HCl}$ $(50 \mu \mathrm{l} / \mathrm{ml})$ was added to the plasma for measurement of total ghrelin.

$\mathrm{PYY}_{3-36}$ and PP concentrations in plasma were measured by in-house RIA with a detection limit of $1 \mathrm{pmol} / \mathrm{l}$. Total ghrelin concentration in plasma was measured by RIA (Linco Research, St Charles, Missouri, USA) with a detection limit of $0.93 \mathrm{pg} / \mathrm{ml}$. The intra- and interassay coefficients of variation (CV) were 3.3-10 and $14.7-17.8 \%$ respectively. GLP-1 concentrations in plasma were measured by RIA after extraction of plasma 
with $70 \%$ ethanol (vol/vol, final concentration). Carboxy-terminal GLP-1 immunoreactivity was determined using antiserum 89390 (14), which has an absolute requirement for the intact amidated carboxy-terminus of GLP-1 7-36 amide, and cross-reacts $<0.01 \%$ with carboxy-terminally truncated fragments and $89 \%$ with GLP-1 9-36 amide, the primary metabolite of dipeptidyl peptidase IV-mediated degradation. The sum of the two components (total GLP-1 concentration) reflects the rate of secretion of the L-cell. The detection limit was $<5 \mathrm{pmol} / \mathrm{l}$, and intra-assay CV was $<10 \%$. In order to estimate oxyntomodulin (and glicentin) concentrations, total glucagon concentrations were measured in plasma after extraction of plasma with $70 \%$ ethanol (vol/vol, final concentration). The glucagon RIA is directed against a mid sequence of the glucagon molecule comprising residues nos 6-15 (antibody code no. 4304) and, therefore, measures all glucagon-containing peptide moieties of pancreatic and intestinal origin $(15,16)$, including glicentin and oxyntomodulin. Standards were human glucagons, and tracer was monoiodinated human glucagon (both gifts from NovoNordisk, Bagsværd, Denmark). The detection limit was $<2 \mathrm{pmol} / \mathrm{l}$, intra-assay $\mathrm{CV}<6 \%$ at $40 \mathrm{pmol} / \mathrm{l}$, and recovery of standard (glucagon), added to plasma before extraction, about 100\% when corrected for losses inherent in the plasma extraction procedure. Plasma CCK concentrations were measured by CCK-specific RIA without cross-reactivity with any gastrin (17). The detection limit was $0.1 \mathrm{pmol} / \mathrm{l}$, and the intra- and interassay variations at different concentrations ranged between 5 and 15\% (17).

\section{Homeostasis model assessment index}

Homeostasis model assessment of insulin resistance (HOMA-IR) was estimated as described by Matthews et al. (18) (HOMA-IR = fasting insulin $(\mathrm{mU} / \mathrm{l}) \times$ fasting plasma glucose $(\mathrm{mmol} / \mathrm{l}) / 22.5)$.

\section{Statistical analysis}

Results are presented as mean \pm s.E.M. Data was logarithmically transformed before analysis when appropriate and statistically analyzed using paired Student's t-test. When the distribution of the data was not normal after logarithmic transformation, they were analyzed using Wilcoxon signed-rank test. Significance level was set at 0.05. First, the effect of treatment with olanzapine ODT was compared with olanzapine OST. Secondly, to evaluate the effect of treatment with olanzapine, the mean of values in response to treatment with olanzapine OST and olanzapine ODT was calculated and compared with values measured in the control group. All analysis was performed using SPSS for Windows, version 12.0 (SPSS Inc., Chicago, IL, USA).

\section{Results}

\section{Subjects}

Twelve subjects (age: $25.1 \pm 5.5$ years) were enrolled in the study (19); ten subjects completed all study occasions. Two subjects did not finish their third study occasion for personal reasons, one missing treatment with olanzapine ODT, and the other treatment with olanzapine OST. The third subject who completed all study occasions was nauseous and vomited after dinner at one study occasion; at this particular occasion, the 'dinner' data were excluded from the statistical analysis. None of the subjects using olanzapine had major side effects. However, most subjects felt tired during the first days of the treatment.

\section{Olanzapine concentration}

Minimum plasma olanzapine concentration $\left(C_{\min }\right)$ was $13.5 \pm 1.3$ and $15.4 \pm 1.5 \mu \mathrm{g} / \mathrm{l}$ during treatment with olanzapine ODT and OST respectively and did not differ between groups $(P=0.18)$.

\section{Anthropometric variables and metabolic profile in fasting condition}

There was no difference in BMI, waist-to-hip ratio, or fat percentage between treatment conditions as we reported earlier (19). Treatment with olanzapine (ODT and OST) significantly $(P=0.005)$ increased HOMA-IR (19) as compared with the control group, where the effect of ODT and OST did not differ. There was no difference in fasting glucose concentrations (control: $4.7 \pm 0.1 \mathrm{mmol} / \mathrm{l}$; olanzapine OST: $4.4 \pm 0.2 \mathrm{mmol} / \mathrm{l}$; olanzapine ODT: $4.1 \pm 0.2 \mathrm{mmol} / \mathrm{l}$ ) between treatment groups, while fasting insulin concentrations increased slightly (control: $7.3 \pm 1.1 \mathrm{mU} / \mathrm{l}$; olanzapine OST: $9.4 \pm 1.1 \mathrm{mU} / \mathrm{l}$; olanzapine ODT: $8.9 \pm 1.2 \mathrm{mU} / \mathrm{l})$, although not significantly $(P=0.053)$. Fasting free fatty acids significantly decreased during olanzapine treatment $(P=0.013$ one tailed; control: $0.520 \pm 0.065$, olanzapine OST: $0.383 \pm 0.025 \mathrm{mmol} / \mathrm{l}$, olanzapine ODT: $0.034 \pm 0.038 \mathrm{mmol} / \mathrm{l}$ ), while there was no difference between the effects of ODT and OST on these parameters (20).

\section{Fasting and preprandial gut peptide concentrations}

With exception of ghrelin concentrations at dinner and CCK concentrations at breakfast, which were both slightly increased in the treatment groups (respectively $P=0.048, P=0.042$ ), treatment with olanzapine did not affect preprandial gut hormone concentrations at dinner or fasting gut hormone concentrations. Gut peptide concentrations were similar during treatment with olanzapine ODT and OST (Table 1, Figs 1 and 2). 
Table 1 Fasting and preprandial gut hormones at breakfast and dinner: without intervention (control), during treatment with olanzapine oral standard tablets (Ola-OST) and orally disintegrating tablets (Ola-ODT).

\begin{tabular}{|c|c|c|c|c|c|}
\hline Parameter & $\begin{array}{l}\text { Control } \\
(n=10)\end{array}$ & $\begin{array}{c}\text { Ola-OST } \\
(n=10)\end{array}$ & $\begin{array}{l}\text { Ola-ODT } \\
(n=10)\end{array}$ & $\begin{array}{l}\text { Paired } t \text {-test ODT } \\
\text { versus OST }\end{array}$ & $\begin{array}{l}\text { Paired } t \text {-test Co } \\
\text { versus treatment }\end{array}$ \\
\hline Mean PP dinner $(\mathrm{pmol} /)^{\mathrm{a}}$ & $34.2 \pm 8.2$ & $37.5 \pm 8.2$ & $39.2 \pm 10.9$ & NS & NS \\
\hline Mean PP breakfast (pmol/l) & $7.6 \pm 2.3$ & $8.8 \pm 2.0$ & $6.9 \pm 1.7$ & NS & NS \\
\hline Mean PYY dinner $\left(\mathrm{pmol} / \mathrm{l}^{\mathrm{a}}\right.$ & $18.9 \pm 1.5$ & $17.4 \pm 1.3$ & $17.9 \pm 1.5$ & NS & NS \\
\hline Mean PYY breakfast (pmol/l) & $13.1 \pm 2.1$ & $14.7 \pm 1.8$ & $13.4 \pm 1.4$ & NS & NS \\
\hline Mean GLP-1 dinner $(\mathrm{pmol} / \mathrm{l})^{\mathrm{a}}$ & $12.6+1.5$ & $14.2+1.8$ & $15.0+2.7$ & NS & NS \\
\hline Mean GLP-1 breakfast (pmol/l) & $8.4 \pm 1.4$ & $9.7 \pm 1.5$ & $8.6 \pm 1.5$ & NS & NS \\
\hline Mean total glucagon dinner $(\mathrm{pmol} / \mathrm{l})^{\mathrm{a}}$ & $34.1 \pm 3.4$ & $40.8 \pm 5.4$ & $37.3 \pm 4.5$ & NS & NS \\
\hline Mean total glucagon breakfast (pmol/l) & $20.0 \pm 1.5$ & $23.4 \pm 2.4$ & $21.3 \pm 1.7$ & NS & NS \\
\hline Mean ghrelin dinner $(\mathrm{pg} / \mathrm{ml})^{\mathrm{a}}$ & $855 \pm 51$ & $894 \pm 79$ & $974 \pm 64$ & NS & 0.048 \\
\hline Mean ghrelin breakfast (pg/ml) & $882 \pm 61$ & $866 \pm 71$ & $890 \pm 67$ & NS & NS \\
\hline Mean CCK dinner $(\mathrm{pmol} / \mathrm{l})^{\mathrm{a}}$ & $0.93 \pm 0.34$ & $1.20 \pm 0.45$ & $1.28 \pm 0.36$ & NS & NS \\
\hline Mean CCK breakfast (pmol/l) & $0.28 \pm 0.06$ & $0.78 \pm 0.22$ & $0.68 \pm 0.21$ & NS & 0.042 \\
\hline
\end{tabular}

Data are presented as mean \pm s.E.M. CCK, cholecystokinin; GLP-1, glucagon-like peptide-1; PP, pancreatic polypeptide; PYY, peptide YY.

aData missing for one subject (ola-OST).

\section{Postprandial gut peptide concentrations}

Treatment with olanzapine did not affect postprandial gut hormone concentrations (Table 2, Figs 1 and 2) except at dinner when mean ghrelin concentrations were slightly increased in the treatment groups $(P=0.034)$. Postprandial gut peptide concentrations were similar during treatment with olanzapine ODT and OST.

\section{Discussion}

This study shows that short-term treatment with either orally disintegrating or standard olanzapine formulations does not have a major impact on gut hormone concentrations in plasma in healthy men.

The mechanisms underpinning weight gain associated with AP drug use are unclear. Their affinity for central and/or peripheral MA receptors could be involved. A plethora of data suggests that gut hormones have an important physiological role in the regulation of postprandial satiety and energy homeostasis (9). The secretion of gut hormones is mainly stimulated by nutrient content of the gut. The secretion of various hormones is also modulated by monoaminergic neurotransmission, as has been demonstrated for GLP-1, PYY, PP, and ghrelin secretion (13, 21-23). Atypical AP drugs, including olanzapine, block various MA receptors in the CNS. Since the majority of these receptors are also located in the ENS, atypical AP drugs might induce weight by modulating gut hormone secretion. If so, olanzapine ODT might cause less weight gain, as it is absorbed more rapidly allowing less binding to MA receptors in the GI tract.

\section{Ghrelin}

In this study, pre- and postprandial ghrelin concentrations were slightly increased during olanzapine treatment at dinner, but not at breakfast, whereas the effect of olanzapine ODT and OST was similar. Earlier studies have shown that long-term treatment with olanzapine is accompanied by elevated plasma ghrelin concentrations $(24,25)$. In contrast, ghrelin concentrations were either not affected $(26,27)$ or decreased $(28,29)$ by short-term treatment $(2-10$ weeks) with olanzapine. Unfortunately, in the shortterm studies, the number of participants was small, participants were of both sexes, and hormonal status of premenopausal women was not taken into account. This might be of importance, since plasma ghrelin levels in humans are sexually dimorphic, with women in the late follicular phase exhibiting higher concentrations than men (30). The current study indicates that olanzapine does not have a major direct effect on plasma ghrelin levels in men. We therefore infer that ghrelin is not involved in the mechanism(s) underpinning the drug's metabolic effects. Long-term treatment with olanzapine may affect ghrelin secretion indirectly through its effects on body weight and/or composition.

\section{CCK}

Fasting CCK concentrations were slightly increased in the olanzapine-treated groups, while preprandial concentrations at dinner and postprandial concentrations at both breakfast and dinner were not affected. CCK concentrations were similar during treatment with olanzapine ODT and OST. To our knowledge, no data are available on the effect of olanzapine on plasma CCK concentrations. Weickert et al. recently showed that hyperinsulinemic euglycemia in healthy men resulted in up to a fivefold increase in circulating CCK concentrations that rapidly declined during lipid infusion and were negatively correlated with free fatty acids (FFA) concentrations (31). This interesting finding suggests that a negative feedback mechanism of circulating FFA on CCK concentration may exist. One might consider 

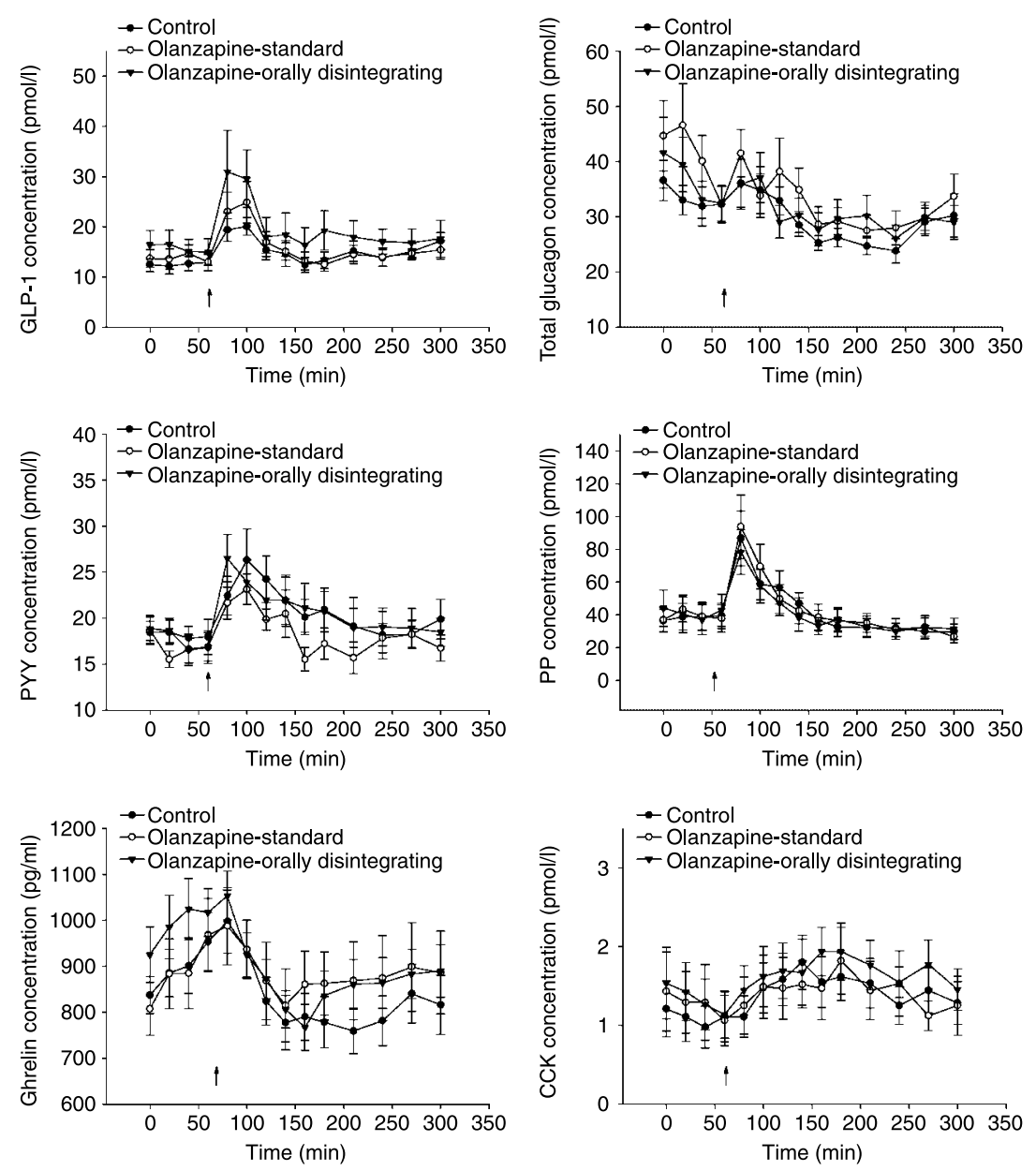

Figure 1 Gut hormone concentrations at dinner. Data are presented as mean \pm s.E.M. $\uparrow$, ingestion of meal. CCK, cholecystokinin; GLP-1, glucagon-like peptide-1; PP, pancreatic polypeptide; PYY, peptide YY.

whether the slight increase in fasting circulating CCK concentrations by olanzapine treatment is caused by suppression of circulating FFA concentrations.

\section{PP and PYY}

PP and PYY concentrations were not affected by olanzapine treatment. To our knowledge, no data are available on the effect of olanzapine on plasma PP and PYY concentrations in humans or animals. In rodents, long-term treatment with olanzapine significantly reduced PYY-binding densities in different parts of the brain when compared to control- and haloperidol-treated groups (32). This finding suggests that olanzapine might counteract the central effect of PYY on satiety. However, our data suggest that olanzapine does not modulate PP or PYY secretion to induce metabolic anomalies.

\section{GLP-1}

GLP-1 concentrations were similar in all treatment groups. To our knowledge, no data are available on the effect of olanzapine or other atypical AP drugs on plasma GLP-1 concentrations. GLP-1 secretion from intestinal human L-cells is stimulated by M1 and M2 muscarinergic receptor agonists and blocked by a muscarinic antagonist (12). Olanzapine is among the AP drugs with the highest affinity for muscarinic receptors, although its affinity is relatively low when compared with atropine (33), which may account for the lack of its abilities to affect plasma GLP-1 levels.

\section{Total glucagons}

Total glucagon concentrations were measured in order to estimate oxyntomodulin (and glicentin) concentrations in response to meals. The total glucagon concentrations were similar in all study groups, and the effects of olanzapine ODT and OST did not differ. There was a rather large increase in total glucagon concentrations in response to breakfast, which did not show any sign of decline $240 \mathrm{~min}$ after breakfast (Fig. 1). The concentrations were still high before dinner but showed a small additional increase in response to the meal (Fig. 2). These findings are similar to the (diurnal) responses to meals described by Holst 

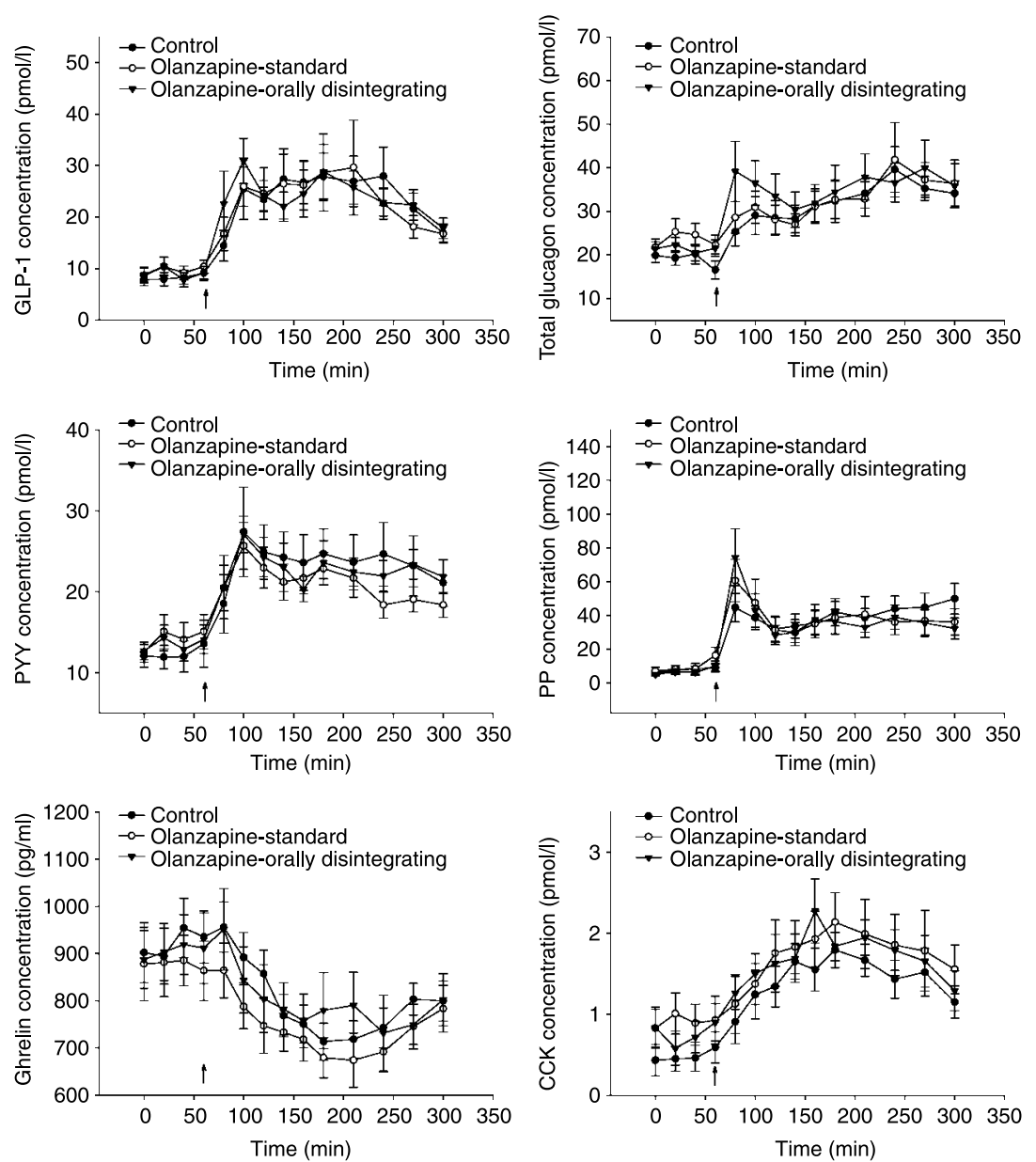

Figure 2 Gut hormone concentrations at breakfast. Data are presented as mean \pm S.E.M. $\uparrow$, ingestion of meal. CCK, cholecystokinin; GLP-1, glucagon-like peptide-1; PP, pancreatic polypeptide; PYY, peptide YY. et al. and Le Quellec et al. (34, 35). In humans, oxyntomodulin reduced food intake by $25 \%$ and repeated preprandial s.c. administration resulted in significant weight loss in overweight and obese subjects (36). Interestingly, oxyntomodulin (OXM) also increased activity-related energy expenditure in obese humans (37) and prevented food induced suppression of TSH secretion in rats when administered intracerebroventricularly (38). It should be noted that it is impossible to distinguish which glucagon-containing moieties contributed to the postprandial increase in the total glucagon concentration. Glucagon from

Table 2 Postprandial gut hormones at breakfast and dinner: without intervention (control), during treatment with olanzapine standard tablets (Ola-OST) and orally disintegrating tablets (Ola-ODT).

\begin{tabular}{|c|c|c|c|c|c|}
\hline Parameter & $\begin{array}{l}\text { Control } \\
(n=10)\end{array}$ & $\begin{array}{l}\text { Ola-OST } \\
(n=10)\end{array}$ & $\begin{array}{l}\text { Ola-ODT } \\
(n=10)\end{array}$ & $\begin{array}{c}\text { Paired } t \text {-test } \\
\text { ODT versus OST }\end{array}$ & $\begin{array}{l}\text { Paired } t \text {-test Co } \\
\text { versus treatment }\end{array}$ \\
\hline Mean PP dinner $(\mathrm{pmol} / \mathrm{I})^{\mathrm{a}}$ & $42.1 \pm 7.8$ & $40.8 \pm 6.4$ & $40.3 \pm 7.6$ & NS & NS \\
\hline Mean PP breakfast (pmol/l) & $36.1 \pm 7.0$ & $33.9 \pm 7.6$ & $37.4 \pm 7.6$ & NS & NS \\
\hline Mean PYY dinner $(p m o l / l)^{a}$ & $22.2 \pm 2.5$ & $19.1 \pm 1.4$ & $21.4 \pm 2.2$ & NS & NS \\
\hline Mean PYY breakfast (pmol/l) & $25.3 \pm 3.9$ & $22.0 \pm 1.7$ & $23.2 \pm 2.2$ & NS & NS \\
\hline Mean GLP-1 dinner (pmol/lá ${ }^{a}$ & $14.9 \pm 1.3$ & $16.9 \pm 1.8$ & $18.7 \pm 3.3$ & NS & NS \\
\hline Mean total glucagon dinner $(\mathrm{pmol} / \mathrm{l})^{\mathrm{a}}$ & $29.4 \pm 2.2$ & $32.5 \pm 3.5$ & $30.7 \pm 3.0$ & NS & NS \\
\hline Mean total glucagon breakfast (pmol/l) & $33.0 \pm 4.0$ & $32.9 \pm 4.2$ & $36.5 \pm 5.5$ & NS & NS \\
\hline Mean ghrelin dinner $(\mathrm{pg} / \mathrm{ml})^{a}$ & $780 \pm 47$ & $892 \pm 87$ & $862 \pm 47$ & NS & 0.034 \\
\hline Mean ghrelin breakfast (pg/ml/) & $774 \pm 35$ & $736 \pm 46$ & $788 \pm 64$ & NS & NS \\
\hline Mean CCK dinner $(\mathrm{pmol} / \mathrm{l})^{\mathrm{a}}$ & $1.38 \pm 0.33$ & $1.39 \pm 0.37$ & $1.61 \pm 0.28$ & NS & NS \\
\hline Mean CCK breakfast (pmol/l) & $1.38 \pm 0.23$ & $1.79 \pm 0.37$ & $1.68 \pm 0.25$ & NS & NS \\
\hline
\end{tabular}

Data are presented as mean \pm s.E.M. CCK, cholecystokinin; GLP-1, glucagon-like peptide-1; PP, pancreatic polypeptide; PYY, peptide YY.

a Data missing for one subject (ola-OST). 
the pancreas is also likely to contribute, but would be expected to reduce food intake if anything (39). There is currently no specific analysis for oxyntomodulin available.

The results of this short-term study suggest that olanzapine-induced weight gain is not caused by modulation of the secretion of gut hormones we measured here. Obviously, we cannot exclude the possibility that olanzapine impacts on other gut peptides (e.g. bombesin, acylated ghrelin) to modulate insulin sensitivity and body weight. Alternatively, olanzapine might act as a competitive inhibitor of central gut hormone receptors preventing their physiological effects. In rodents, olanzapine reduced PYY-binding densities in different parts of the brain (32), indicating that the drug might indeed counteract the central effects of PYY. In a recent study, olanzapine exhibited a negligible affinity for a number of anorexigenic neuroreceptors, including those of CCK (40). Unfortunately, the drug's affinity for GLP-1, PYY, and OXM receptors was not studied. Furthermore, the weight gaining properties of olanzapine might either be associated with its peripheral effect on serotonin receptors in the pylorus as proposed by de Haan et al. (5) or with its affinity for MA receptors in the CNS, in particular the hypothalamus and the brain stem. Indeed, the distinct weight-inducing properties of olanzapine ODT and OST, which were recently confirmed in two clinical studies $(41,42)$, may be ascribed to their different pharmacodynamic characteristics. Arranz et al. (4) proposed that partial sublingual absorption of the ODT formulation, partly bypassing gastrointestinal metabolization, might alter the parent to metabolite concentration ratio. They state that two of olanzapine's metabolites would be devoid of activity at central receptors. If true, ODT and OST may differ in their effect on the CNS.

Activation of histamine $\mathrm{H} 1$, serotonin $5-\mathrm{HT}$ (2C in particular), $\alpha-1$ adrenergic, and dopamine D2 receptors are known to inhibit food intake and reduce body weight (43-47). All these MA receptors are blocked by olanzapine. Neuroendocrine effects of olanzapine might also account for its weight-inducing properties. We recently showed that short-term treatment with olanzapine shifts the temporal relationship of the acrophase of prolactin and cortisol in healthy men (19). Similar endocrine patterns are known to presage weight gain in a variety of obese animal models (48). Finally, treatment with AP is often complicated by tiredness/drowsiness, which might diminish physical activity and thereby induce weight gain. However, we did not detect differences in physical activity (by accelerometer) or resting energy expenditure (by indirect calorimetry) during short-term treatment with olanzapine (20). Notably, this study was conducted in active healthy young men and not in patients with psychiatric disorders, which might be of importance for the level of physical activity.
The small sample size is a limitation of this study; However, its crossover design increases the statistical power. Indeed, if we take fasting PYY levels as an example, the study has $85 \%$ power to detect a difference of $5.0 \mathrm{pmol} / \mathrm{l}$ with an alpha error level of $5 \%$ in a twosided paired $t$-test, given an average baseline value of 18.2 with a s.D. of $3.9 \mathrm{pmol} / \mathrm{l}$ (s.E.M. is given in the table). As stated before, we measured the plasma concentration of a variety, but not all gut hormones in response to olanzapine treatment. Therefore, the data do not exclude the possibility that the drug impacts on one of the other hormones to affect insulin action and body weight.

In conclusion, short-term treatment with olanzapine does not have a major impact on the plasma concentrations of gut hormones we measured in healthy men. Moreover, despite the pharmacological differences of the two oral olanzapine formulations, the concentration of these hormones was similar during treatment with ODT and OST. Weight gain and diabetes during olanzapine treatment are therefore unlikely to be caused by modulation of the secretion of gut hormones measured here. We cannot exclude the possibility that olanzapine impacts on other gut hormones to impair insulin sensitivity and stimulate weight gain.

\section{Declaration of interest}

All authors declare that they have no conflict of interest.

\section{Funding}

The research described in this article was supported by the Dutch Diabetes Foundation (2002.01.005) and was partly funded by Eli Lilly (Houten, The Netherlands).

\section{Acknowledgements}

We thank the research assistants of the Clinical Research Center of the General Internal Medicine Department of Leiden University Medical Center (E J M Ladan-Eijgenraam and I A Sierat-van der Steen) for their assistance during the study.

\section{References}

1 Henderson DC, Cagliero E, Gray C, Nasrallah RA, Hayden DL, Schoenfeld DA \& Goff DC. Clozapine, diabetes mellitus, weight gain, and lipid abnormalities: a five-year naturalistic study. American Journal of Psychiatry 2000157 975-981.

2 Allison DB, Mentore JL, Heo M, Chandler LP, Cappelleri JC, Infante MC \& Weiden PJ. Antipsychotic-induced weight gain: a comprehensive research synthesis. American Journal of Psychiatry $19991561686-1696$.

3 Newcomer JW. Abnormalities of glucose metabolism associated with atypical antipsychotic drugs. Journal of Clinical Psychiatry $20046536-46$

4 Arranz B, San L, Duenas RM, Centeno M, Ramirez N, Salavert J \& Del Moral E. Lower weight gain with the orally disintegrating olanzapine than with standard tablets in first-episode never treated psychotic patients. Human Psychopharmacology 200722 11-15. 
5 de Haan L, van Amelsvoort T, Rosien K \& Linszen D. Weight loss after switching from conventional olanzapine tablets to orally disintegrating olanzapine tablets. Psychopharmacology 2004175 389-390.

6 Markowitz JS, DeVane CL, Malcolm RJ, Gefroh HA, Wang JS, Zhu HJ \& Donovan JL. Pharmacokinetics of olanzapine after singledose oral administration of standard tablet versus normal and sublingual administration of an orally disintegrating tablet in normal volunteers. Journal of Clinical Pharmacology $2006 \mathbf{4 6}$ 164-171.

7 Bergstrom RF, Mitchell M, Witcher J, Houston JP, Hill AL, Taylor CC, Liu-Seifert H, Yadav Marya R \& Jones B. Rapid onset of absorption with olanzapine orally disintegrating tablets. Endocrine Society 2005. 2005 (Ref Type: Abstract).

8 Grundy D \& Schemann M. Enteric nervous system. Current Opinion in Gastroenterology 200521 176-182.

9 Cummings DE \& Overduin J. Gastrointestinal regulation of food intake. Journal of Clinical Investigation 2007117 13-23.

10 Rindi G, Necchi V, Savio A, Torsello A, Zoli M, Locatelli V, Raimondo F, Cocchi D \& Solcia E. Characterisation of gastric ghrelin cells in man and other mammals: studies in adult and fetal tissues. Histochemistry and Cell Biology 2002117 511-519.

11 Anini Y, Hansotia T \& Brubaker PL. Muscarinic receptors control postprandial release of glucagon-like peptide-1: in vivo and in vitro studies in rats. Endocrinology $20021432420-2426$.

12 Anini Y \& Brubaker PL. Muscarinic receptors control glucagonlike peptide 1 secretion by human endocrine L cells. Endocrinology $20031443244-3250$.

13 Zhang T, Uchida T, Gomez G, Lluis F, Thompson JC \& Greeley GH Jr. Neural regulation of peptide YY secretion. Regulatory Peptides 199348 321-328.

14 Orskov C, Rabenhoj L, Wettergren A, Kofod H \& Holst JJ. Tissue and plasma concentrations of amidated and glycine-extended glucagon-like peptide I in humans. Diabetes 199443 535-539.

15 Holst JJ, Christiansen J \& Kuhl C. The enteroglucagon response to intrajejunal infusion of glucose, triglycerides, and sodium chloride, and its relation to jejunal inhibition of gastric acid secretion in man. Scandinavian Journal of Gastroenterology 197611 297-304.

16 Holst JJ. Evidence that enteroglucagon (II) is identical with the C-terminal sequence (residues 33-69) of glicentin. Biochemistry Journal $1982 \mathbf{2 0 7} 381-388$.

17 Rehfeld JF. Accurate measurement of cholecystokinin in plasma. Clinical Chemistry 199844 991-1001.

18 Matthews DR, Hosker JP, Rudenski AS, Naylor BA, Treacher DF \& Turner RC. Homeostasis model assessment: insulin resistance and beta-cell function from fasting plasma glucose and insulin concentrations in man. Diabetologia $1985 \mathbf{2 8} 412-419$.

19 Vidarsdottir S, Roelfsema F, Frolich M \& Pijl H. Olanzapine shifts the temporal relationship between the daily acrophase of serum prolactin and cortisol concentrations rhythm in healthy men. Psychoneuroendocrinology 200934 705-712.

20 Vidarsdottir S, Vlug P, Roelfsema F, Frolich M \& Pijl H. Orally disintegrating and standard olanzapine tablets similarly elevate the HOMA insulin resistance index and plasma triglyceride levels in healthy men. Journal of Clinical Psychiatry (In Press).

21 Ao Y, Go VL, Toy N, Li T, Wang Y, Song MK, Reeve JR Jr, Liu Y \& Yang H. Brainstem thyrotropin-releasing hormone regulates food intake through vagal-dependent cholinergic stimulation of ghrelin secretion. Endocrinology $20061476004-6010$.

22 Deacon CF. What do we know about the secretion and degradation of incretin hormones? Regulatory Peptides $2005 \mathbf{1 2 8} 117-124$.

23 Greenberg GR, Chan B, Nordgren SR \& Alleyne J. Effect of vagal blockade on food- and hormone-stimulated release of pancreatic polypeptide and motilin in dogs. Digestive Diseases and Sciences 198530 946-953.

24 Murashita M, Kusumi I, Inoue T, Takahashi Y, Hosoda H, Kangawa K \& Koyama T. Olanzapine increases plasma ghrelin level in patients with schizophrenia. Psychoneuroendocrinology $200530106-110$.
25 Palik E, Birkas KD, Faludi G, Karadi I \& Cseh K. Correlation of serum ghrelin levels with body mass index and carbohydrate metabolism in patients treated with atypical antipsychotics. Diabetes Research and Clinical Practice 200568 S60-S64.

26 Himmerich H, Fulda S, Kunzel HE, Pfennig A, Dzaja A, Cummings DE \& Pollmacher T. Ghrelin plasma levels during psychopharmacological treatment. Neuropsychobiology $2005 \mathbf{5 2}$ 11-16.

27 Theisen FM, Gebhardt S, Bromel T, Otto B, Heldwein W, HeinzelGutenbrunner M, Krieg JC, Remschmidt H, Tschop M \& Hebebrand J. A prospective study of serum ghrelin levels in patients treated with clozapine. Journal of Neural Transmission 2005112 1411-1416.

28 Hosojima H, Togo T, Odawara T, Hasegawa K, Miura S, Kato Y, Kanai A, Kase A, Uchikado H \& Hirayasu Y. Early effects of olanzapine on serum levels of ghrelin, adiponectin and leptin in patients with schizophrenia. Journal of Psychopharmacology 2006 20 75-79.

29 Togo T, Hasegawa K, Miura S, Hosojima H, Kojima K, Shoji M, Kase A, Uchikado H, Iseki E \& Kosaka K. Serum ghrelin concentrations in patients receiving olanzapine or risperidone. Psychopharmacology 2004172 230-232.

30 Barkan AL, Dimaraki EV, Jessup SK, Symons KV, Ermolenko M \& Jaffe CA. Ghrelin secretion in humans is sexually dimorphic, suppressed by somatostatin, and not affected by the ambient growth hormone levels. Journal of Clinical Endocrinology and Metabolism $2003 \mathbf{8 8} 2180-2184$.

31 Weickert MO, Mohlig M, Spranger J, Schofl C, Loeffelholz CV, Riepl RL, Otto B \& Pfeiffer AF. Effects of euglycemic hyperinsulinemia and lipid infusion on circulating cholecystokinin. Journal of Clinical Endocrinology and Metabolism $2008932328-2333$.

32 Wang $Q$ \& Huang XF. Effects of chronic treatment of olanzapine and haloperidol on peptide YY binding densities in the rat brain. Experimental Neurology $2008209261-267$.

33 Richelson E. Receptor pharmacology of neuroleptics: relation to clinical effects. Journal of Clinical Psychiatry 199960 5-14.

34 Holst JJ, Schwartz TW, Lovgreen NA, Pedersen O \& Beck-Nielsen H. Diurnal profile of pancreatic polypeptide, pancreatic glucagon, gut glucagon and insulin in human morbid obesity. International Journal of Obesity 19837 529-538.

35 Le QA, Kervran A, Blache P, Ciurana AJ \& Bataille D. Oxyntomodulin-like immunoreactivity: diurnal profile of a new potential enterogastrone. Journal of Clinical Endocrinology and Metabolism 199274 1405-1409.

36 Wynne K, Park AJ, Small CJ, Patterson M, Ellis SM, Murphy KG, Wren AM, Frost GS, Meeran K, Ghatei MA \& Bloom SR. Subcutaneous oxyntomodulin reduces body weight in overweight and obese subjects: a double-blind, randomized, controlled trial. Diabetes $2005 \mathbf{5 4} 2390-2395$.

37 Wynne K, Park AJ, Small CJ, Meeran K, Ghatei MA, Frost GS \& Bloom SR. Oxyntomodulin increases energy expenditure in addition to decreasing energy intake in overweight and obese humans: a randomised controlled trial. International Journal of Obesity 200630 1729-1736.

38 Dakin CL, Small CJ, Park AJ, Seth A, Ghatei MA \& Bloom SR. Repeated ICV administration of oxyntomodulin causes a greater reduction in body weight gain than in pair-fed rats. American Journal of Physiology. Endocrinology and Metabolism $2002 \mathbf{2 8 3}$ E1173-E1177.

39 Geary N. Pancreatic glucagon signals postprandial satiety. Neuroscience and biobehavioral reviews 199014 323-338.

40 Theisen FM, Haberhausen M, Firnges MA, Gregory P, Reinders JH, Remschmidt H, Hebebrand J \& Antel J. No evidence for binding of clozapine, olanzapine and/or haloperidol to selected receptors involved in body weight regulation. Pharmacogenomics Journal $20077275-281$.

41 Crocq MA, Guillon MS, Bailey PE \& Provost D. Orally disintegrating olanzapine induces less weight gain in adolescents than standard oral tablets. European Psychiatry $200722453-454$. 
42 Chawla B \& Luxton-Andrew H. Long-term weight loss observed with olanzapine orally disintegrating tablets in overweight patients with chronic schizophrenia. A 1 year open-label, prospective trial. Human Psychopharmacology 200823 211-216.

43 Masaki T, Chiba S, Yasuda T, Noguchi H, Kakuma T, Watanabe T, Sakata T \& Yoshimatsu H. Involvement of hypothalamic histamine $\mathrm{H} 1$ receptor in the regulation of feeding rhythm and obesity. Diabetes 200453 2250-2260.

44 Nonogaki K, Strack AM, Dallman MF \& Tecott LH. Leptinindependent hyperphagia and type 2 diabetes in mice with a mutated serotonin 5-HT2C receptor gene. Nature Medicine 19984 1152-1156.

45 Pijl H. Reduced dopaminergic tone in hypothalamic neural circuits: expression of a "thrifty" genotype underlying the metabolic syndrome? European Journal of Pharmacology $2003 \mathbf{4 8 0} 125-131$.
46 Wellman PJ, Davies BT, Morien A \& McMahon L. Modulation of feeding by hypothalamic paraventricular nucleus alpha 1- and alpha 2-adrenergic receptors. Life Sciences 199353 669-679.

47 Wirshing DA, Wirshing WC, Kysar L, Berisford MA, Goldstein D, Pashdag J, Mintz J \& Marder SR. Novel antipsychotics: comparison of weight gain liabilities. Journal of Clinical Psychiatry 199960 358-363.

48 Meier A \& Cincotta AH. Circadian rhythms regulate the expression of the thrifty genotype/phenotype. Diabetes Reviews $1996 \mathbf{4}$ 464-487.

Received 14 August 2009

Accepted 4 September 2009 